Review

\title{
Nail Psoriasis: Diagnosis, Assessment, Treatment Options, and Unmet Clinical Needs
}

\author{
Gurjit S. Kaeley ${ }^{1}$ (D), Lihi Eder ${ }^{2}$ (D), Sibel Zehra Aydin ${ }^{3}(\mathbb{D})$, Phoebe Rich ${ }^{4}$, and Catherine J. Bakewell ${ }^{5}$
}

ABSTRACT. Objective. An estimated 40-50\% of patients with psoriasis ( $\mathrm{PsO}$ ) have psoriatic nail disease, which is associated with and directly contributes to a greater clinical burden and worse quality of life in these patients. In this review, we examine how recent advances in the use of new diagnostic techniques have led to improved understanding of the link between nail and musculoskeletal manifestations of psoriatic disease (PsD; e.g., enthesitis, arthritis) and we review targeted therapies for nail $\mathrm{PsO}$ (NP).

Methods. We performed a literature search to identify which systemic therapies approved for the treatment of $\mathrm{PsO}$ and/or psoriatic arthritis (PsA) have been evaluated for the treatment of NP, either as a primary or secondary outcome. A total of 1546 articles were identified on February 18, 2019, and evaluated for relevance. Results. We included findings from 66 articles on systemic therapies for the treatment of NP in PsD. With several scoring systems available for the evaluation of psoriatic nail disease, including varied subtypes and application of the Nail Psoriasis Area Severity Index, there was a high level of methodological heterogeneity across studies.

Conclusion. NP is an important predictor of enthesitis, which is associated with the early stages of PsA; therefore, it is important for rheumatologists and dermatologists to accurately diagnose and treat NP to prevent nail damage and potentially delay the onset and progression of joint disease. Further research is needed to address the lack of both standardized NP scoring systems and well-defined treatment guidelines to improve management of PsD.

Key Indexing Terms: psoriasis, psoriatic arthritis, spondyloarthropathy

Psoriasis $(\mathrm{PsO})$ is a chronic, immune-mediated inflammatory skin disease that affects approximately $2-3 \%$ of the population. ${ }^{1,2}$ Among patients with $\mathrm{PsO}$, an estimated $40-50 \%$ have psoriatic

This study is funded by Novartis Pharmaceuticals Corporation, East

Hanover, New Jersey, USA.

${ }^{1}$ G.S. Kaeley, MRCP, Department of Medicine, University of Florida College of Medicine, Division of Rheumatology, Jacksonville, Florida, USA ${ }^{2} L$. Eder, MD, PhD, University of Toronto, Women's College Research Institute, Toronto, Ontario, Canada; ${ }^{3}$ S.Z. Aydin, MD, University of Ottawa, Faculty of Medicine, Ottawa, Ontario, Canada; ${ }^{4}$ P. Rich, MD, Oregon Dermatology \& Research Center, Portland, Oregon, USA; ${ }^{5}$ C.J. Bakewell, MD, Salt Lake Clinic, Salt Lake City, Utah, USA.

$G S K$ has received consultancy fees from Novartis. $L E$ received research and educational grants or consultancy fees from AbbVie, Amgen, Pfizer, Janssen, Eli Lilly, Novartis, and Celgene. $S Z A$ has received consultancy fees from AbbVie, Celgene, Eli Lilly, Janssen, Novartis, Pfizer, and UCB. PR has received research funding from AbbVie, Bristol Myers Squibb, Cellceutix (now Innovation Pharmaceuticals), Eli Lilly, Kadmon Holdings, Sun Pharmal Merck, and UCB. CJB has received consultancy fees from and/or served on speakers bureaus for AbbVie, Novartis, Pfizer, and Sanofi Genzymel Regeneron.

Address correspondence to Dr. G.S. Kaeley, University of Florida College of Medicine, Division of Rheumatology, 653-1 West 8th St, LRC 2nd Floor L-14, Jacksonville, FL 32209-6561, USA. Email: Gurjit.Kaeley@jax.ufl.edu.

Accepted for publication February 2, 2021. nail disease, and lifetime prevalence of nail $\mathrm{Ps} \mathrm{O}(\mathrm{NP})$ is as high as $90 \% .{ }^{3,45,6}$ However, in $5-10 \%$ of cases, NP manifests in the absence of cutaneous symptoms. ${ }^{7,8}$

Nail involvement is associated with greater severity of $\mathrm{PsO}^{3}$ and is more common in patients with joint involvement. NP is an independent predictor of psoriatic arthritis (PsA). ${ }^{9}$ The reported prevalence of NP in patients with PsA has varied between cohorts, from 32-97\% (average 66\%), according to a recent systematic review. ${ }^{10} \mathrm{NP}$ is also associated with decreased quality of life (QOL) in patients with $\mathrm{PsO}$ and/ or PsA, ${ }^{11,12}$ may cause severe pain, and may be associated with an increased prevalence of anxiety and depression. ${ }^{13}$ Patients with NP often have difficulty putting on shoes or socks and struggle to perform certain daily household activities, which leads to worse health-related QOL and reduced work productivity. Because nails, especially fingernails, are highly visible and difficult to conceal, NP can cause embarrassment and self-consciousness, and many patients feel stigmatized by what is perceived as a disfiguring disease. ${ }^{11,14}$

The nail is connected to underlying bone through an enthesis network that is fused with the extensor tendon crossing the distal interphalangeal (DIP) joint (Figure 1). ${ }^{15}$ This anatomical connection of the nail matrix to the musculoskeletal system means that NP can be an early indicator of PsA ${ }^{16,17,18,19}$; therefore, there is a need for awareness and understanding of nail disease 

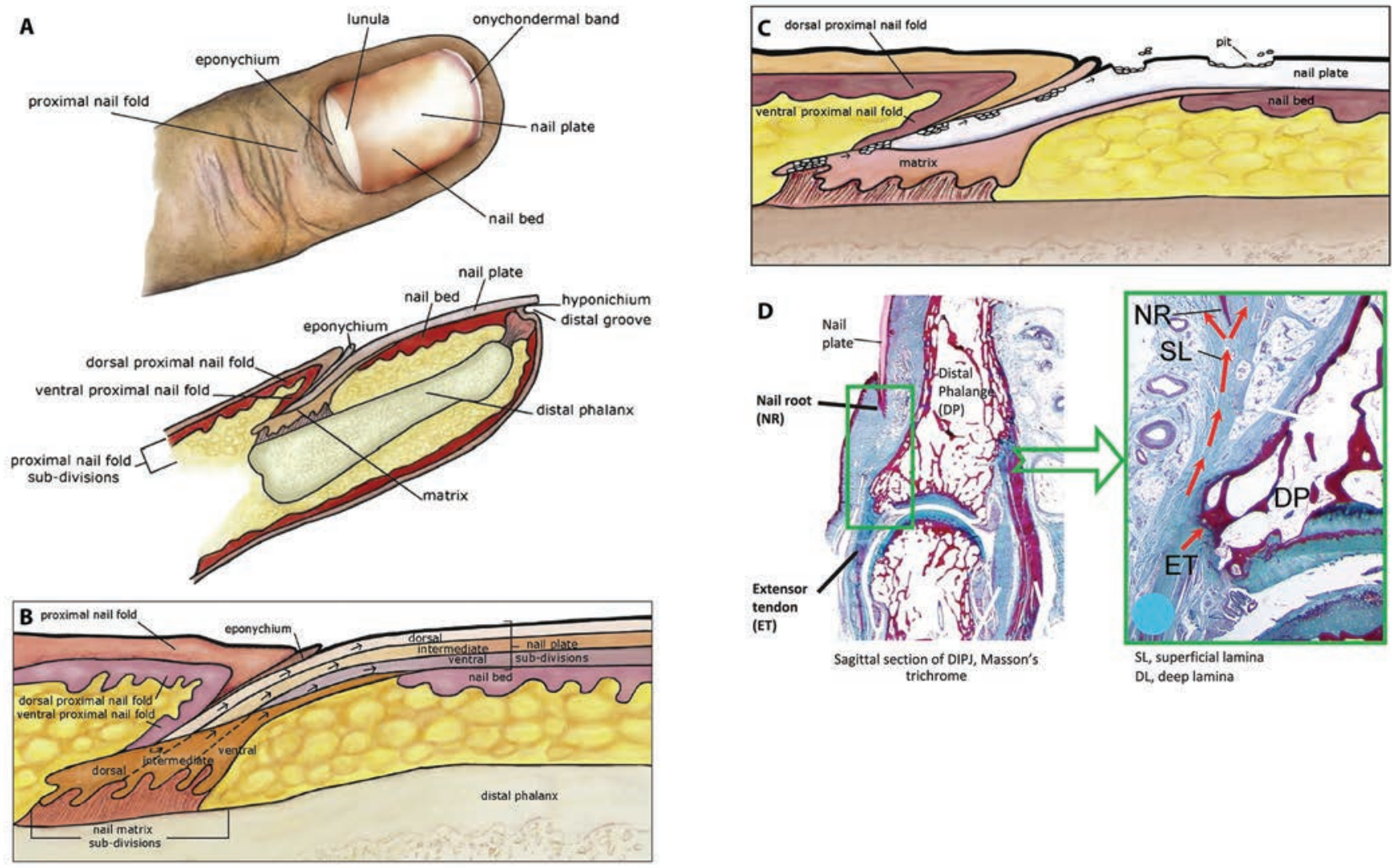

Figure 1. (A) Structural components of the nail unit. (B) The subdivisions of the nail matrix. (C) Pit formation in the nail plate arising from the nail matrix. ${ }^{5}$ (D) Anatomical relationship between the nail and distal interphalangeal extensor tendon enthesitis: histology sections showing the superficial lamina and deep lamina from the extensor tendon are associated with the nail root and matrix. ${ }^{15}$ (A), (B), and (C) reprinted from Jiaravuthisan MM, Sasseville D, Vender RB, Murphy F, Muhn CY. Psoriasis of the nail: anatomy, pathology, clinical presentation, and a review of the literature on therapy. J Am Acad Dermatol 2007; 57:1-27. Copyright 2007, with permission from Elsevier. (D) Reproduced from Tan AL, Benjamin M, Toumi H, Grainger AJ, Tanner SF, Emery P, et al. The relationship between the extensor tendon enthesis and the nail in distal interphalangeal joint disease in psoriatic arthritis-a high-resolution MRI and histological study. Rheumatology 2007;46:253-6. Copyright 2009: the author. Journal compilation copyright 2009: European Academy of Dermatology and Venereology. Adapted from: Tan AL, et al. Rheumatology 2007;46:253-256 by permission of Oxford University Press.

\section{A. Nail matrix psoriasis}

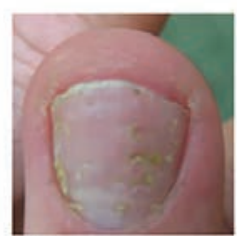

Pitting, leukonychia

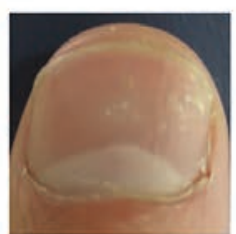

Leukonychia

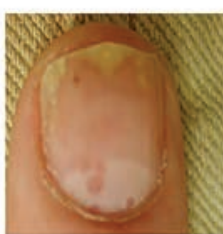

Red macules in lunula

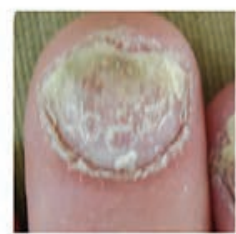

Crumbling

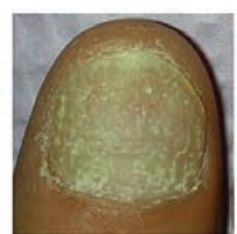

Trachyonychia

B. Nail bed psoriasis

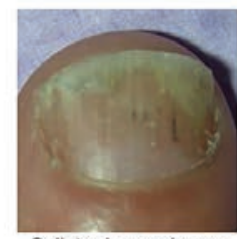

Splinter hemorrhages and onycholysis

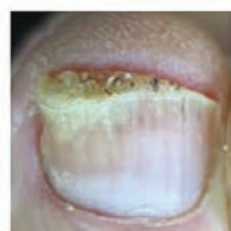

Hyperkeratosis and splinter hemorrhages

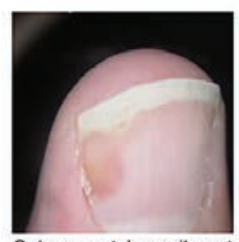

Salmon patch or oil spot dyschromia

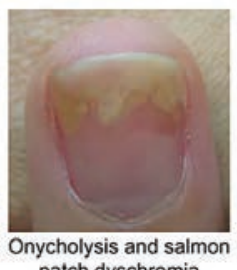

patch dyschromia

Figure 2. Examples of (A) nail matrix and (B) nail bed psoriasis. ${ }^{10}$ Images courtesy of Phoebe Rich, MD. 
among rheumatologists, primary care providers, and dermatologists to improve identification and management of PsA.

Our review (1) provides an overview of NP, (2) discusses the use of new diagnostic techniques with a focus on the resulting improved understanding of the link between nail and musculoskeletal manifestations of psoriatic disease (PsD), and (3) reviews the current targeted therapies for NP. Literature search details are provided in the Supplementary Data (available with the online version of this article).

\section{Overview of the nail unit}

The nail unit is composed of 4 epithelial structures-the nail matrix, the nail bed, the hyponychium, and the proximal and lateral nail folds, which function to produce, attach, and protect the nail plate (Figure 1). ${ }^{5,13}$ The nail matrix cells differentiate into the hard, rectangular, translucent structure we refer to as the nail plate, which is nonliving tissue and hence, technically, not part of the nail unit. The hyponychium and the lateral and proximal nail folds act as seals to prevent environmental pathogens and irritants from penetrating the nail unit and causing disease.

The primary function of the nail is to protect the digits from injury, enhance fine motor function of the digits, and to scratch in defense or to quell itches. The healthy nail plate is translucent, hard, and colorless in all people and derives its apparent color from underlying structures. The white semicircular structure in the proximal nail, called the lunula, represents the distal portion of the nail matrix seen through the proximal nail plate. The highly vascularized nail bed results in the apparent pink color of the nail, while the white free edge of the nail plate is due to air underneath and explains the white color of the lifted nail plate in onycholysis.

The nail matrix produces the nail plate by differentiation of nail matrix keratinocytes into flattened onychocytes, without the formation of keratohyalin granules. Sheets of matrix squamous cells flatten and are closely packed in lamella of the nail plate. Sulfurous proteins and calcium phosphate provide strength and flexibility to nail plate keratin. The rate of nail plate growth limits the time scale over which changes can be observed. In healthy individuals, nail elongation speed (NES) is approximately $0.1 \mathrm{~mm} /$ day; in people with $\mathrm{PsO}$, NES increases by around $10-25 \% .20,21$

The nail bed firmly attaches to the ventral aspect of the nail plate by way of parallel longitudinal ridges and grooves that interlock with and bind the nail plate tightly to the nail bed as it grows distally. Nail bed epithelium does not produce keratohyalin granules and does not have a granular layer-unlike the nail folds and hyponychium, which exhibit the keratinization typical of normal volar skin. The nail bed also contains a rich vascular system within the parallel longitudinal grooves between the ridges, which explains the orientation of splinter hemorrhages within the nail bed. ${ }^{5,13}$

Because of the anatomy of the nail unit and its connection to the DIP joints, the presence of NP can serve as a predictor for development of PsA, especially of extensor tendon enthesopathy of the DIP joints. ${ }^{16,17,18,19}$ This association has been linked to the anatomical connection between the nail matrix and the entheses of the DIP joints (Figure 1). The nail is anchored to underlying bone by a "mini-enthesis network," whereby the extensor tendon that crosses the DIP is fused with the nail matrix and nail root. ${ }^{15}$ This may explain why patients with PsA, who usually present with enthesitis of the DIP joint, also frequently (although not always) present with nail changes characteristic of NP.

\section{Diagnosis and assessment of NP}

Overview. NP can occur in all portions of the nail unit, and the clinical features of NP, such as pitting, onycholysis, and crumbling, depend on which part of the nail unit is affected by the psoriatic inflammatory process (Figure 2)..$^{10,12,13,22,23}$ The symptoms of nail matrix $\mathrm{Ps} O$ depend on the precise location of $\mathrm{PsD}$ in the proximal or distal matrix, as well as the transverse extent and duration of the disease process. Pitting, crumbling, and leukonychia are caused by foci of $\mathrm{PsO}$ pathology in the nail matrix that forms the nail plate. Other less common nail matrix features include Beau lines (deep horizontal indentations), onychomadesis (separation of the nail plate from the nail matrix), trachyonychia (rough, ridged nails), and total nail plate dystrophy. $\mathrm{PsO}$ in the nail bed causes oil-drop (salmon patch) dyschromia, nail bed hyperkeratosis, and splinter hemorrhages-all of which disrupt nail plate attachment-and, eventually, onycholysis. $\mathrm{PsO}$ of the proximal and lateral nail folds resembles $\mathrm{PsO}$ on other skin sites. The cuticle attachment can be destroyed by $\mathrm{PsO}$ of the nail folds, which results in nail plate surface irregularities similar to those observed in paronychia.

Diagnosis. NP can usually be diagnosed based on clinical features in patients with accompanying skin and/or joint symptoms of PsD. ${ }^{13}$ In the absence of diagnosed skin or joint PsD, NP can be difficult to differentiate from other causes of nail dystrophy, and idiopathic nail dystrophy should be part of the differential diagnosis. ${ }^{13,23,24}$ The clinical presentation of NP can vary greatly based on the part of the nail unit that is affected (Figure 2). NP color changes, hyperkeratosis, onychorrhexis, and nail plate thickening often resemble onychomycosis, which is frequently observed in up to $60 \%$ of patients with $\mathrm{PsO}$. Changes in the distal or marginal nail plate can resemble lichen planus.

Biopsies can provide information on histopathologic nail changes that can inform difficult diagnoses, but nail biopsies are rarely performed because they are invasive procedures associated with bleeding, pain, permanent scarring, nail dystrophy, and increased risk for secondary infection. ${ }^{24,25,26}$ Nail clippings can be analyzed to identify fungal infection, parakeratosis, and subungual hyperkeratosis. ${ }^{27,28}$

Imaging techniques, including high-resolution ultrasound, dermoscopy, videodermoscopy, optical coherence tomography, capillaroscopy, and confocal laser scanning microscopy, are increasingly being used as noninvasive diagnostic tools for identifying various features of NP and response to treatment. ${ }^{26,29,30,31,32,33}$ Once NP is diagnosed, it is important for clinicians to be able to assess its severity in order to determine an optimal treatment strategy and to monitor the response to therapy. ${ }^{34}$

\section{Nail assessment and scoring systems}

Overall clinical severity has been described using the fingernail physician global assessment (f-PGA), $35,36,37$ by which 
the fingernails are assessed for nail plate pitting, crumbling, onycholysis, oil-drop discoloration, and/or nail bed hyperkeratosis on a 5-point scale, from 0 (clear) to 4 (severe), and by simple visual analog scale (VAS; used in some PsA trials). The need for more precise outcome measures to determine therapeutic efficacy in clinical trials has led to several more complex scoring systems (Table 1 ).

The Nail PsO Area Severity Index (NAPSI) is the most widely used tool for scoring NP in clinical trials. Using the NAPSI, each nail is divided into 4 quadrants and scored based on the presence or absence of psoriatic changes to the nail matrix and the nail bed (Figure 3). ${ }^{38,39}$ The NAPSI usually assesses fingernails, for a total score of $0-80$, but some studies have also included the toenails (scoring 0-160; Table 2). The NAPSI is the only system that explicitly separates nail matrix and nail bed symptoms.

A modified version of the NAPSI (mNAPSI), used in several clinical trials to date, demonstrated superior interrater variability and correlations with patient and physician global assessments. ${ }^{40}$ Scoring of the mNAPSI is based on the whole of each fingernail, to avoid variability in defining quadrants. Four abnormalities are scored as 0 (absent) or 1 (present): leukonychia, splinter hemorrhages, hyperkeratosis, and red spots in the lunula. Three other abnormalities are scored between 0 and 3, depending on their extent: the percentage area of onycholysis and oil-drop dyschromia (considered together, as they are part of the same pathological process) is scored as 0 (none), 1 (1-10\%), $2(11-30 \%)$, or 3 (> 30\%); the number of pits is scored as 0 (none), 1 (1-10 pits), 2 (11-49 pits), or 3 ( $\geq 50$ pits); and the percentage area of nail plate crumbling is scored as 0 (none), 1 $(1-25 \%), 2(26-50 \%)$, or $3(>50 \%) \cdot{ }^{40}$ The total range of fingernail scores for mNAPSI is $0-130$. By assessing the nail as a whole rather than by quadrant, the mNAPSI eliminates a source of variation, but this may reduce its sensitivity to early changes in response to treatment.

A common strategy to simplify follow-up assessments has been the use of a target nail, in which only the baseline worst affected nail is quantified at follow-up. In the original NAPSI paper, the authors suggested that a "target NAPSI" could be scored by the presence or absence of each of the 4 nail bed and 4 nail matrix anomalies in each quadrant of a single nail, for a score ranging from 0 to $32 .{ }^{39} \mathrm{~A}$ "modified target NAPSI" (not to be confused with mNAPSI) was subsequently proposed, in which each of the 8 nail anomalies in each quadrant were scored as 0 (none), 1 (mild), 2 (moderate), or 3 (severe), for a total score of $0-96 .{ }^{41}$ However, neither of these more complex target nail systems are commonly used-most studies reporting data on target nails have used the regular NAPSI or mNAPSI applied to a single nail, for a score of $0-8$ or $0-13$ (Table 2).

Five other nail scoring systems are used less frequently: (1) Psoriasis Nail Severity Score, ${ }^{42,43}$ (2) Baran system, ${ }^{44}$ (3) Cannavò system, ${ }^{45}$ (4) Nail Area Severity score, ${ }^{46}$ and (5) Nijmegen-Nail PsO Activity Index tool (N-NAIL), which combines the elements from other systems that best predicted clinical assessments (Table 1). ${ }^{34}$

Table 1. Comparison of nail scoring systems used in studies of currently approved treatments for PsO and/or PsA.

\begin{tabular}{|c|c|c|c|c|c|c|}
\hline Symptoms & & $\begin{array}{l}\text { NAPSI, }{ }^{38,39} \\
\text { by Quadrant }\end{array}$ & $\begin{array}{c}\text { Target NAPSI, }{ }^{38,39} \\
\text { per Quadrant }\end{array}$ & $\begin{array}{l}\text { mNAPSI, }{ }^{38,40} \\
\text { Whole Nail }\end{array}$ & $\begin{array}{l}\text { N-NAIL, }{ }^{34} \\
\text { Whole Nail }\end{array}$ & $\begin{array}{l}\text { f-PGA, }{ }^{80} \\
\text { All Nails }\end{array}$ \\
\hline \multirow[t]{3}{*}{ Nail matrix symptoms } & Beau lines & - & - & - & $\begin{array}{c}\text { Absent }=0 ; 1 \text { line }=1 ; \\
2 \text { lines }=2 ; \geq 3 \text { lines }=3\end{array}$ & $\begin{array}{c}\text { Clear }=0 \\
\text { Minimal }=1\end{array}$ \\
\hline & Leukonychia & $\begin{array}{c}\text { Score } 1 \text { for each } \\
\text { nail quadrant with } \\
\text { nail matrix symptoms }(0-4)\end{array}$ & Present $=1$ & Present $=1$ & - & $\begin{array}{c}\text { Mild }=2 ; \\
\text { Moderate }=3 ; \\
\text { Severe }=4\end{array}$ \\
\hline & Red spots in the lunula & & Present $=1$ & Present $=1$ & - & \\
\hline & Onycholysis & & Present $=1$ & & & \\
\hline & Splinter hemorrhages & & Present $=1$ & Present $=1$ & - & \\
\hline \multicolumn{5}{|l|}{ Score range per nail } & $0-15$ & $0-4$ \\
\hline Total for fingernails & & $0-80$ & - & $0-130^{\mathrm{a}}$ & $0-150$ & $0-4$ \\
\hline Total for all nails & & $0-160$ & - & - & - & $0-4$ \\
\hline
\end{tabular}

${ }^{2}$ Note that the mNAPSI is sometimes listed as 0-14 per nail, 0-140 total, due to a misprint in the original paper. ${ }^{40} \mathrm{f}$-PGA: fingernail physician global assessment; mNAPSI: modified NAPSI; NAPSI: Nail Psoriasis Area Severity Index; N-NAIL: Nijmegen-Nail Psoriasis Activity Index Tool; PsA: psoriatic arthritis; $\mathrm{PsO}$ : psoriasis. 

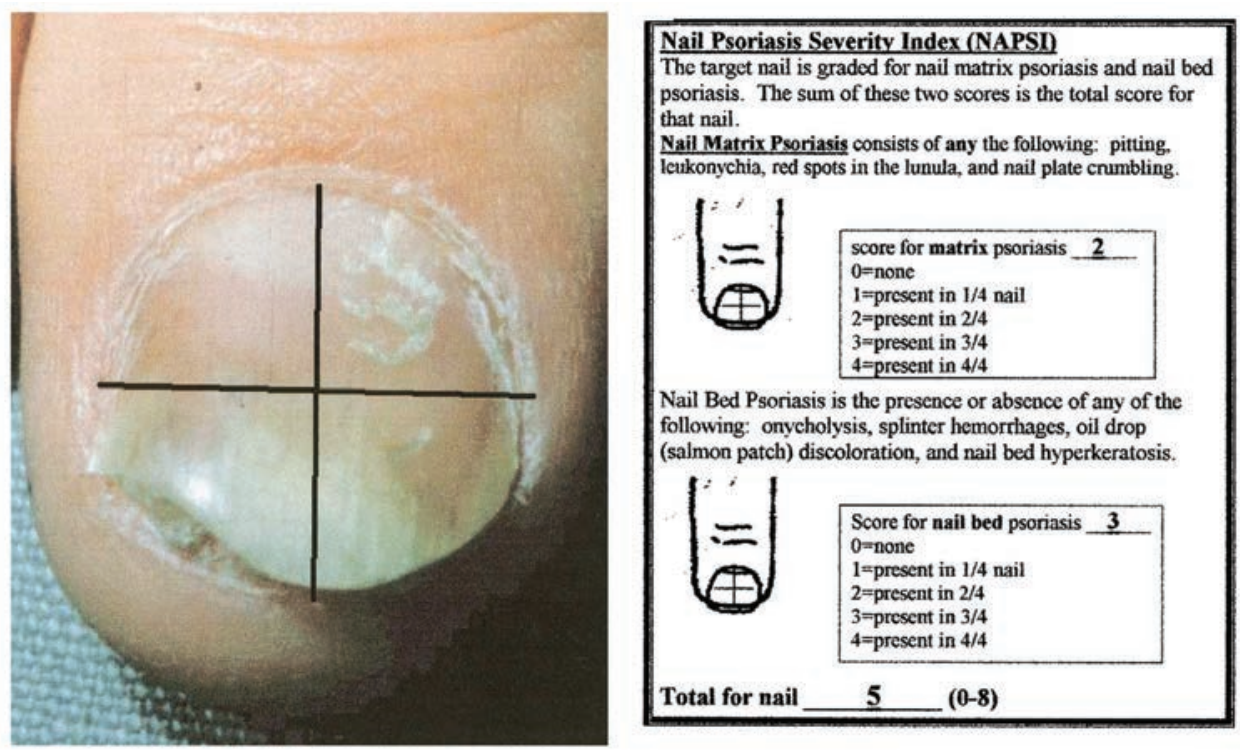

Figure 3. Example of division of a nail into quadrants and instructions for grading using the Nail Psoriasis Severity Index. ${ }^{39}$ Reprinted from Rich P, Scher RK. Nail Psoriasis Area Severity Index: a useful tool for evaluation of nail psoriasis. J Am Acad Dermatol 2003;49:206-12. Copyright 2003, with permission from Elsevier.
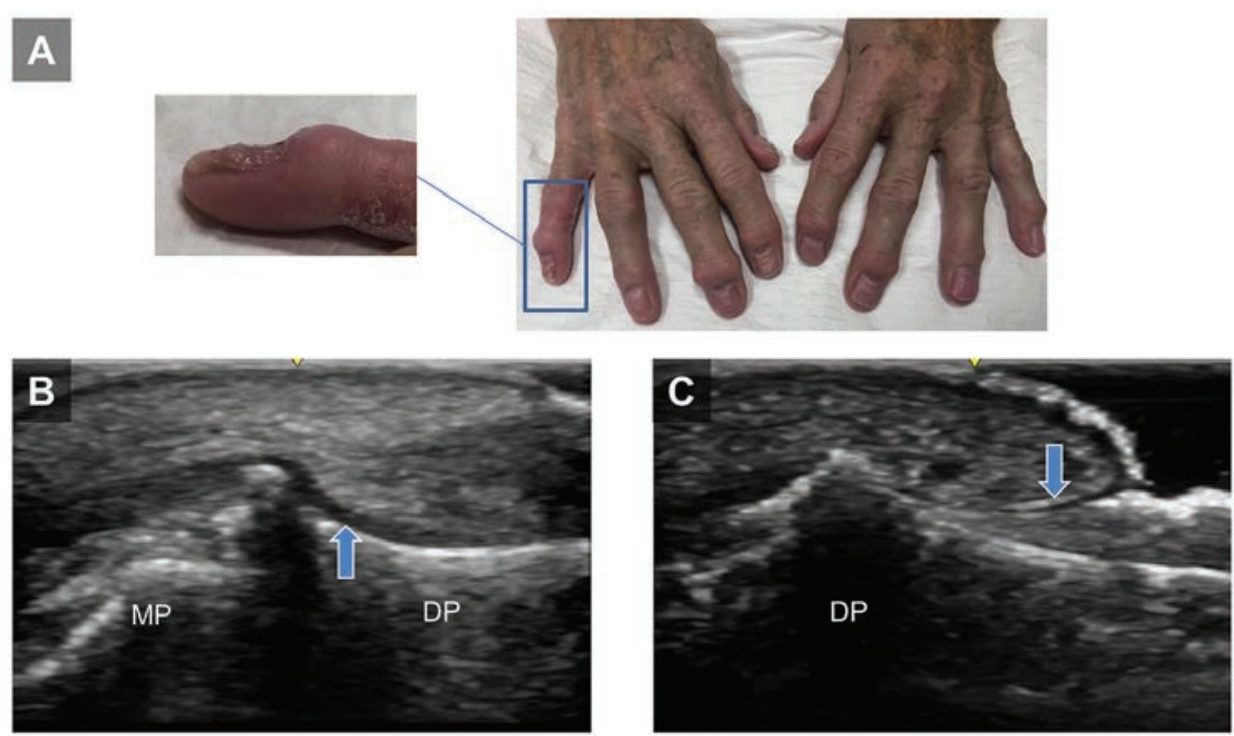

Figure 4. (A) Ultrasound imaging of the nail/enthesis complex in a 64-year-old woman with psoriasis, psoriatic arthritis, and nail disease. (B) Up arrow: extensor tendon fibers split and fuse with the periosteum over the terminal phalanx, which is connected to the nail bed, thus indirectly anchoring the enthesis to the bone of the phalanx. (C) Down arrow: extensor tendon fibers enveloping the nail root. DP: distal phalanx; MP: middle phalanx. Images courtesy of Catherine J. Bakewell, MD.

Scoring systems that have been developed to measure the effect of NP on QOL include the 10-item Nail Psoriasis Quality of Life scale and the Nail Assessment in PsO and PsA; however, published data on the use of these tools are extremely limited. $47,48,49$

Although many nail scoring systems are available, most of these instruments were developed for use in clinical trials and are typically not used in daily practice. Rheumatologists and dermatologists will usually note the presence or absence of nail lesions but may not always use objective scoring methods to evaluate the severity of nail disease or response to treatment. It should also be noted that the reliability of NAPSI when used by nonexpert rheumatologists has been shown to be variable..$^{50}$ Another option is the physician global VAS for NP, which can be performed quickly and easily by clinicians in a busy clinic, making it more likely to be used than a more time-consuming assessment tool such as NAPSI, mNAPSI, or N-NAIL. Although a physician VAS does not provide the same level of detail as other tools and does not differentiate between nail matrix and nail bed pathology, it correlates strongly with the 


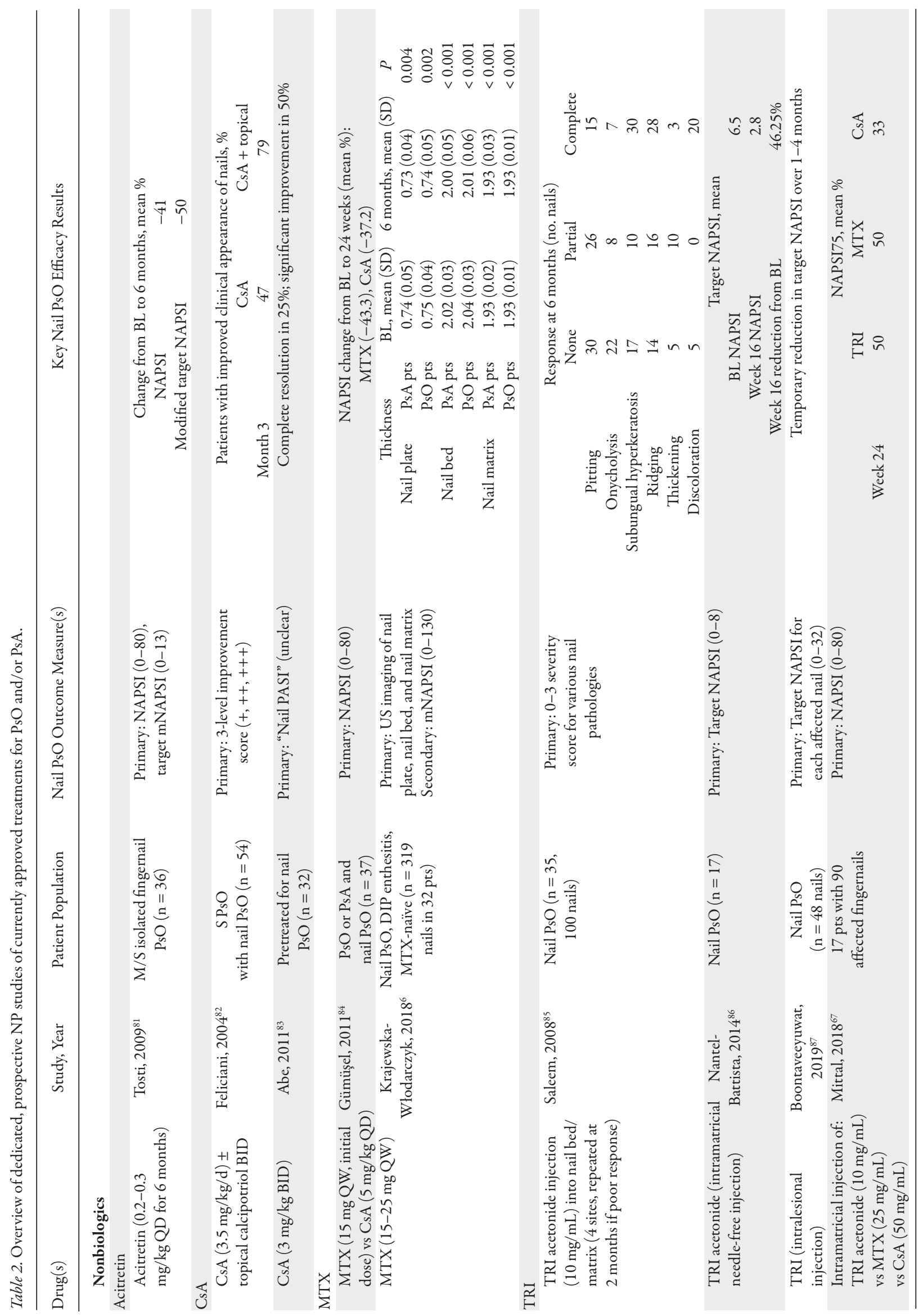




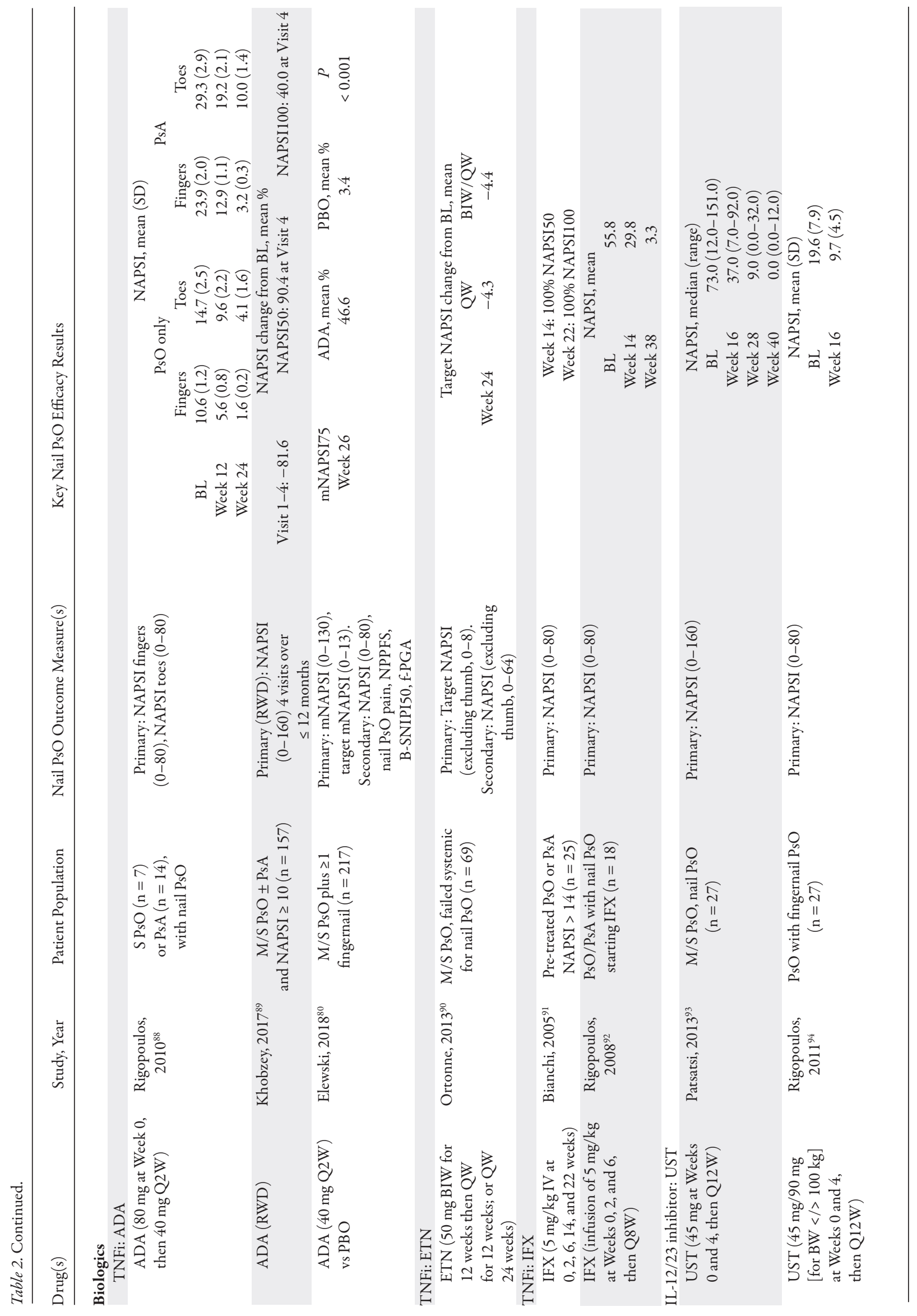




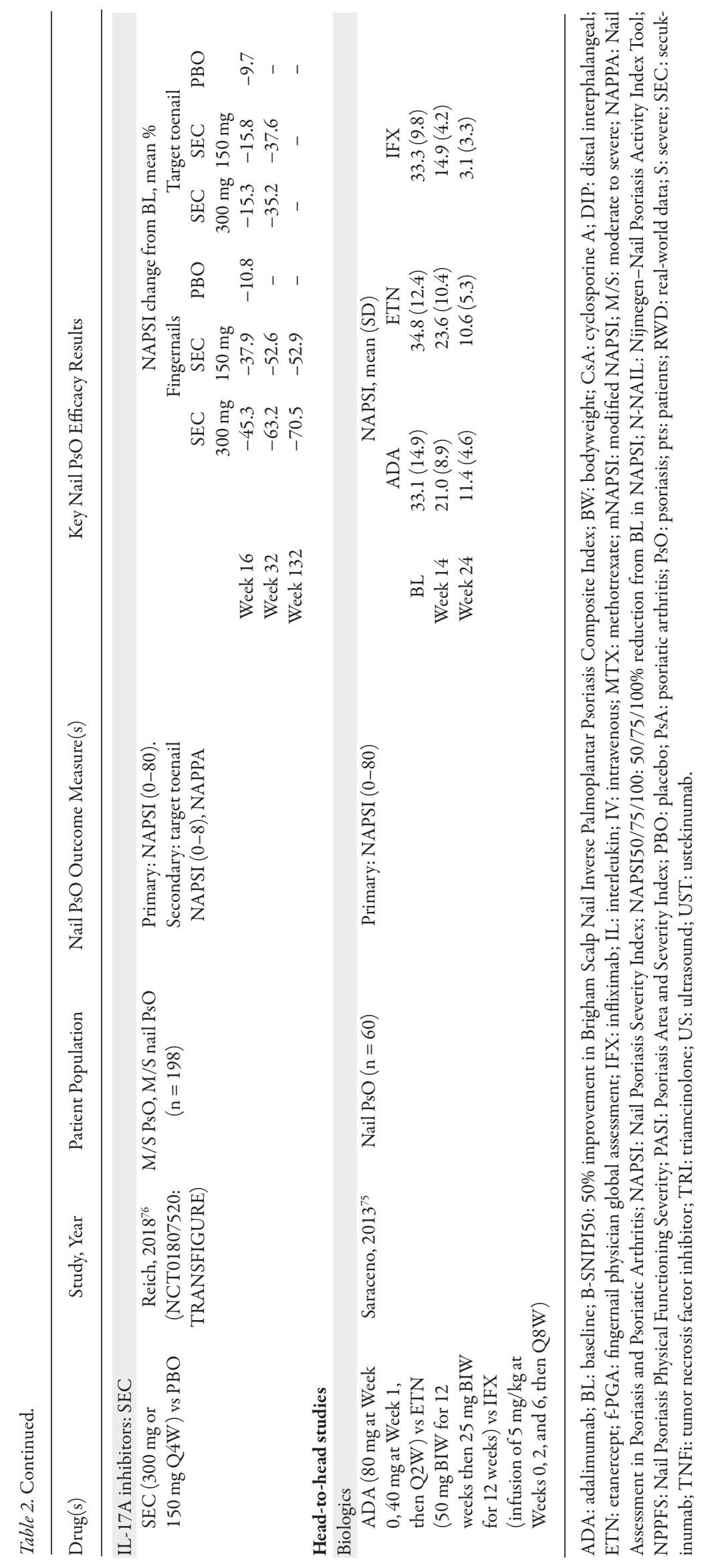


mNAPSI and has excellent internal consistency and interrater reliability. ${ }^{40}$ Currently, there is a lack of consensus on the best NP scoring system, and most available instruments have not been completely validated or do not consider patient-specific factors such as overall burden or effect on QOL. ${ }^{34,47}$

In addition to measures evaluated by physicians, patient global assessments are routinely used in studies of psoriatic conditions, generally based on a VAS. Because skin and joint symptoms are not always of the same severity, it was suggested that patients with PsA be given separate joint- and skin-focused VAS. ${ }^{51}$ Other clinicians subsequently suggested that nail symptoms should also be assessed by a separate VAS and showed that patient global nail VAS scores were moderately correlated to mNAPSI $(p=0.55) .^{52}$

\section{Nail manifestations as indicators of PsA and the importance of imaging}

Early, targeted treatment of NP is important because of the strong association between NP and the development of PsA. ${ }^{16,17,18,19}$ Patients with NP have an almost 3-fold higher risk of developing PsA than patients with $\mathrm{PsO}$ who do not have signs of nail dystrophy. ${ }^{53}$

Enthesitis is typically one of the earliest inflammatory changes observed in PsA, especially in the DIP joints. Development of NP may be the first sign of joint disease resulting from subclinical enthesitis in the closely anatomically associated entheses of the DIP extensor tendons (Figure 1 and Figure 4). ${ }^{18,53,54,55}$ This hypothesis is supported by results from several recent imaging studies showing that changes in the DIP joint capsule are closely linked to histologic nail changes and diffuse inflammatory responses extending from the enthesis to the nail. ${ }^{10,15,16,56,57}$ Specifically, $\mathrm{PsO}$ patients with nail involvement have higher enthesopathy scores on ultrasound than patients without nail disease, as a result of entheseal thickening of the extensor tendon. ${ }^{16,56,57}$ Several studies have shown positive correlations between NAPSI scores and ultrasound evidence of enthesopathy. ${ }^{56,58}$

A recent study comparing nail ultrasound measures in healthy controls to patients with $\mathrm{PsO}$ or PsA found that the nail plate and nail bed were thickened in patients with $\mathrm{PsO}$ or PsA, more so in digits with clinical nail symptoms. ${ }^{59}$ However, another recent study, which also included patients with rheumatoid arthritis and osteoarthritis (OA), found that nail plate thickening was associated with OA and concluded that PsA was best discriminated using the power Doppler signal at the nail enthesis. ${ }^{60}$ Overall, imaging techniques, including ultrasound and magnetic resonance imaging, can provide valuable data on structural and inflammatory changes to the nail unit and anatomically associated joints. Imaging findings generally correlate well with clinical observations and could potentially be used as part of clinical assessments of NP. . $^{16,56,61,62}$ Although only one of the NP clinical studies found in our search (Table 2; Supplementary Table 1, available with the online version of this article), incorporated imaging as a diagnostic or outcome measure, expanded use of imaging should be considered in future research. ${ }^{63}$

\section{Recent developments in the treatment of NP}

Overview of available therapies. In recent years, substantial progress has been made in understanding the pathogenesis of psoriatic skin and joint disease, and several highly effective therapies are now available for the treatment of moderate to severe disease. However, NP research has been far more limited, and determining an appropriate treatment course can be challenging. This leads to the undertreatment of NP, which is a significant unmet need in the management of PsD; in a Dutch Psoriasis Association survey, only $16 \%$ of patients were receiving treatment for NP. ${ }^{48}$

Topical therapies are often used as first-line treatment for mild NP, but efficacy is modest even when disease is limited to minimal dystrophy in 1 or 2 nails. ${ }^{64,65}$ Application of topical therapies to nails is messy, most drugs do not adequately penetrate the nail bed and nail matrix, and use of topical corticosteroids can result in nail and underlying phalanx atrophy, nail striae, telangiectasias, tachyphylaxis, and other adverse consequences associated with systemic absorption of corticosteroids. ${ }^{5,66}$

Available data, generally from cohort studies (Table 2), indicate that intralesional injection of corticosteroids or methotrexate (MTX) directly into the nail matrix can be an effective treatment for NP; however, these procedures are unpopular among patients and physicians because they can be very painful and time consuming, with side effects including subungual hematomas, short-term paresthesia, and atrophy at the injection site. $5,66,67$

The traditional oral systemic therapies - cyclosporine, MTX, acitretin, and leflunomide - generally provide modest efficacy, though many physicians consider these agents to be inadequate or inappropriate for the treatment of NP in the absence of significant skin disease. ${ }^{5,64,66}$

There are now several classes of biologic and small-molecule therapies approved for the treatment of moderate to severe plaque $\mathrm{PsO}$ and/or PsA, including targeted inhibitors of tumor necrosis factor (TNF), interleukin (IL)-12/23, IL-17A, IL-23, phosphodiesterase 4, and Janus kinases. These agents have all demonstrated significant efficacy in psoriatic skin and/or joint disease, but because they are not specifically indicated for the treatment of NP, physicians can face insurance reimbursement challenges in patients with moderate to severe nail disease with minimal or no skin or joint involvement.

\section{Clinical trials evaluating efficacy in NP}

The 1546 articles identified by the literature search for approved systemic drugs included 66 clinical studies that reported outcomes for NP. Nail measures were a primary study outcome in 22 of the included articles, a secondary outcome in 25 articles, and a retrospective or posthoc outcome in the remaining 19. Half of the articles reported data for various patient subgroups, including one with nail symptoms at baseline, and half were analyses that reported data only for patients with nail symptoms. Nineteen articles reported prospective studies dedicated to NP (Table 2), and the remainder were subgroup analyses (Supplementary Table 1, available with the online version of this article). Moderate or severe $\mathrm{PsO} \pm \mathrm{PsA}$ was a clinical trial inclusion criterion in 33 articles, active PsA an inclusion criterion in 9 articles, and $\mathrm{PsO}$ and/or PsA in 6. 
Twenty-two of the included articles reported placebo-controlled trials, including 5 articles reporting trials that also included an active comparator (UNCOVER-3; $;^{68,69}$ VOYAGE 1 and 2;35,37 and LIBERATE $^{70}$ ), and 5 articles reported head-to-head trials with no placebo arm. Sixty-one articles reported trials focused on single agents, including nonbiologics; TNF, IL-12/23, IL-17A, and IL-23 inhibitors; and targeted synthetic disease-modifying antirheumatic drugs.

Perhaps the most notable observation about these studies (Table2; Supplementary Table 1, available with the online version of this article) is the high level of heterogeneity, highlighting the need for a common clinical measure to allow for comparisons across studies. Although many studies used variations of the NAPSI, this index is not standardized and is heterogeneous in its subtypes and application. ${ }^{71}$ Some studies have reported raw scores, some have reported percentage reductions from baseline, and others have reported the proportion of patients meeting percentage reduction thresholds (e.g., NAPSI50) modeled on commonly used Psoriasis Area and Severity Index (PASI) targets, such as PASI75 and PASI100 (Table 2). It is important to note that the relatively slow growth of nails vs skin means that results can take longer to manifest, particularly for toenails, which means that trials may need to have longer follow-up to adequately assess nail outcomes.

The reports for nonbiological treatments had the greatest diversity in nail scoring methods. In the studies where NAPSI was reported, nonbiologics improved NAPSI by $40-50 \%$ after 4-6 months. In general, the biologic therapies were reported to achieve these levels of NAPSI improvement more rapidly, as early as Week 12. Most studies of biologics showed that NAPSI continued to improve, with NAPSI improvements rising to the $70-90 \%$ range for some drug types. Given the broad range of therapies used to treat NP, results from active-comparator studies may help inform treatment decisions. Real-world prospective studies have shown that biologic therapies are generally significantly more effective than conventional therapies. ${ }^{72}$ Comparative studies of different TNF inhibitors have shown that infliximab (IFX) provides greater improvement in NP than etanercept (ETN) or adalimumab (ADA); however, treatment with IFX is associated with higher risk of secondary fungal infection in patients with nail scrapings negative for fungus at baseline. ${ }^{73,74,75}$ Several comparisons between different classes of biologic agents have been undertaken. Treatment with the IL-17A inhibitor ixekizumab provided greater improvement in NP than treatment with the TNF inhibitor ETN over 12 weeks in the UNCOVER-3 study. ${ }^{68,69}$ Data from the VOYAGE $1^{37}$ and VOYAGE $2^{35}$ trials showed that nail improvements with the IL-23 inhibitor guselkumab were comparable to those observed with ADA through 24 weeks of treatment, but f-PGA responses were superior at Week 48. These results suggest that targeting the IL-17-IL-23 pathway may be a more effective long-term NP treatment strategy than blocking TNF. The importance of the IL-17 axis was highlighted in the TRANSFIGURE trial $^{76}$ (NCT01807520), a placebo-controlled study evaluating secukinumab (SEC) specifically in patients with NP. SEC led to NAPSI reductions at 16 and 32 weeks that were superior to placebo and similar to, or numerically greater than, those with other biologics at similar time points.

Accurate comparisons of data between studies are made difficult by the heterogeneity of patient populations in subanalyses investigating NP, the fact that less than one-third of articles reported placebo-controlled trials, and the differing nail outcome measures used. This suggests a need for further placebo-controlled, randomized trials focused on NP. However, the rates of nail growth mean that responses to treatment will not be fully captured during typical placebo-controlled periods of $\leq 24$ weeks. For example, in the TRANSFIGURE trial, between Week 16 (the endpoint of the placebo-controlled phase) and Week 32, nail symptoms continued to improve vs baseline: the mean percentage reduction in fingernail NAPSI was larger at Week 32 vs Week 16 by a factor of 1.4 , and that of the target toenail NAPSI larger by a factor of $2.3^{76}$ (CinicalTrials.gov: NCT01807520).

\section{Guidelines for Treatment of NP}

In 2015, the Group for Research and Assessment of $\mathrm{PsO}$ and PsA (GRAPPA) included NP as one of the 6 key domains of PsA (peripheral arthritis, axial disease, enthesitis, dactylitis, $\mathrm{PsO}$, and nail disease).$^{77}$ For treatment of patients with moderate-to-severe NP, the 2015 GRAPPA treatment guidelines recommended biologic treatment with TNF, IL-12/23, and IL-17 inhibitors, choosing therapy to address as many disease domains as possible.

The recently published "Joint [American Academy of Dermatology-National Psoriasis Foundation] AAD-NPF guidelines of care for the management and treatment of psoriasis with biologics" ${ }^{178}$ recommended biologic monotherapies for treatment of adult patients with moderate to severe plaque $\mathrm{PsO}$ affecting the nails (TNF inhibitors: ADA, ETN, or IFX; IL-12/23 inhibitor: ustekinumab; IL-17 inhibitors: SEC or ixekizumab).

\section{Conclusions}

$\mathrm{NP}$ is an important predictor of enthesitis associated with the early stages of $\mathrm{Ps} A$, as patients with $\mathrm{PsO}$ are 3 times more likely to develop PsA if they have nail symptoms. The nail sits at a fascinating nexus of the appendicular and musculoskeletal system due to the close relationship of the extensor tendon enthesis to nail structures. NP is 1 of the 6 key domains of PsA that need to be assessed to establish the prognosis and optimal treatment for individual patients. ${ }^{77,79}$ As such, it is important for rheumatologists and dermatologists to accurately diagnose and treat NP to potentially delay the onset and progression of joint disease. However, given that systemic therapies are not specifically indicated for the treatment of NP in the absence of moderate to severe skin or joint disease, there are several unmet needs in daily practice, including the lack of a simple, validated, and widely accepted NP scoring system and well-defined treatment guidelines for patients with NP without moderate or severe skin symptoms or active PsA. Further randomized studies investigating treatment of NP are needed to gather a more comprehensive pool of data. Recent imaging studies have provided important data on the anatomical link between NP and musculoskeletal 
manifestations of PsD. Expanded use of imaging modalities could be a valuable way to inform NP diagnosis and treatment decisions.

\section{ACKNOWLEDGMENT}

The authors thank Amos Race, PhD, of ArticulateScience LLC, Hamilton, NJ, USA, for providing medical writing support/editorial support, which was funded by Novartis Pharmaceuticals Corporation, East Hanover, NJ, in accordance with Good Publication Practice (GPP3) guidelines (http:// www.ismpp.org/gpp3).

\section{ONLINE SUPPLEMENT}

Supplementary material accompanies the online version of this article.

\section{REFERENCES}

1. Parisi R, Symmons DP, Griffiths CE, Ashcroft DM; Identification and Management of Psoriasis and Associated ComorbidiTy (IMPACT) project team. Global epidemiology of psoriasis: a systematic review of incidence and prevalence. J Invest Dermatol 2013;133:377-85.

2. Rachakonda TD, Schupp CW, Armstrong AW. Psoriasis prevalence among adults in the United States. J Am Acad Dermatol 2014;70:512-6.

3. Armesto S, Esteve A, Coto-Segura P, Drake M, Galache C, Martínez-Borra J, et al. [Nail psoriasis in individuals with psoriasis vulgaris: a study of 661 patients]. [Article in Spanish] Actas Dermosifiliogr 2011;102:365-72.

4. Augustin M, Reich K, Blome C, Schäfer I, Laass A, Radtke MA. Nail psoriasis in Germany: epidemiology and burden of disease. $\mathrm{Br} \mathrm{J}$ Dermatol 2010;163:580-5.

5. Jiaravuthisan MM, Sasseville D, Vender RB, Murphy F, Muhn CY. Psoriasis of the nail: anatomy, pathology, clinical presentation, and a review of the literature on therapy. J Am Acad Dermatol 2007; 57:1-27.

6. Baran R. The burden of nail psoriasis: an introduction. Dermatology 2010;221 Suppl 1:1-5.

7. Langley RG, Daudén E. Treatment and management of psoriasis with nail involvement: a focus on biologic therapy. Dermatology 2010;221 Suppl 1:29-42.

8. Salomon J, Szepietowski JC, Proniewicz A. Psoriatic nails: a prospective clinical study. J Cutan Med Surg 2003;7:317-21.

9. Rigopoulos D, Baran R, Chiheb S, Daniel CR 3rd, Di Chiacchio N, Gregoriou S, et al. Recommendations for the definition, evaluation, and treatment of nail psoriasis in adult patients with no or mild skin psoriasis: a dermatologist and nail expert group consensus. J Am Acad Dermatol 2019;81:228-40.

10. Sandre MK, Rohekar S. Psoriatic arthritis and nail changes: exploring the relationship. Semin Arthritis Rheum 2014;44:162-9.

11. Klaassen KM, van de Kerkhof PC, Pasch MC. Nail psoriasis, the unknown burden of disease. J Eur Acad Dermatol Venereol 2014;28:1690-5.

12. Manhart R, Rich P. Nail psoriasis. Clin Exp Rheumatol 2015; 33:S7-13.

13. Sobolewski P, Walecka I, Dopytalska K. Nail involvement in psoriatic arthritis. Reumatologia 2017;55:131-5.

14. de Jong EM, Seegers BA, Gulinck MK, Boezeman JB, van de Kerkhof PC. Psoriasis of the nails associated with disability in a large number of patients: results of a recent interview with 1,728 patients. Dermatology 1996;193:300-3.

15. Tan AL, Benjamin M, Toumi H, Grainger AJ, Tanner SF, Emery P, et al. The relationship between the extensor tendon enthesis and the nail in distal interphalangeal joint disease in psoriatic arthritis-a high-resolution MRI and histological study. Rheumatology 2007;46:253-6.

16. Aydin SZ, Castillo-Gallego C, Ash ZR, Marzo-Ortega H, Emery P, Wakefield RJ, et al. Ultrasonographic assessment of nail in psoriatic disease shows a link between onychopathy and distal interphalangeal joint extensor tendon enthesopathy. Dermatology 2012;225:231-5.

17. Lai TL, Pang HT, Cheuk YY, Yip ML. Psoriatic nail involvement and its relationship with distal interphalangeal joint disease. Clin Rheumatol 2016;35:2031-7.

18. Raposo I, Torres T. Nail psoriasis as a predictor of the development of psoriatic arthritis. Actas Dermosifiliogr 2015;106:452-7.

19. Watad A, Eshed I, McGonagle D. Lessons learned from imaging on enthesitis in psoriatic arthritis. Isr Med Assoc J 2017;19:708-11.

20. Dawber R. Fingernail growth in normal and psoriatic subjects. Br J Dermatol 1970;82:454-7.

21. Honma $M$, Iinuma $S$, Takahashi $H$, Iizuka $H$, Ishida-Yamamoto A. Accelerated nail elongation speed in psoriasis patients during treatment. J Dermatol 2015;42:910-1.

22. Nieradko-Iwanicka B. Nail psoriasis - what a rheumatologist should know about. Reumatologia 2017;55:44-7.

23. Schons KR, Knob CF, Murussi N, Beber AA, Neumaier W, Monticielo OA. Nail psoriasis: a review of the literature. An Bras Dermatol 2014;89:312-7.

24. Grover C, Reddy BS, Uma Chaturvedi K. Diagnosis of nail psoriasis: importance of biopsy and histopathology. Br J Dermatol 2005;153:1153-8.

25. Kaul S, Singal A, Grover C, Sharma S. Clinical and histological spectrum of nail psoriasis: a cross-sectional study. J Cutan Pathol 2018;45:824-30

26. Marina ME, Solomon C, Bolboaca SD, Bocsa C, Mihu CM, Tătaru AD. High-frequency sonography in the evaluation of nail psoriasis. Med Ultrason 2016;18:312-7.

27. Garbers LE, Slongo H, Fabricio LH, Schmitt JV, Bonalumi AF. Incidence, clinical manifestations and clipping of nail psoriasis in the dermatology center of the Hospital Universitario Evangelico de Curitiba. An Bras Dermatol 2016;91:300-5.

28. Lipner SR, Iorizzo M. Clinical pearl: early diagnosis of nail psoriasis and psoriatic arthritis. Cutis 2017;99:138.

29. Aldahan AS, Chen LL, Fertig RM, Holmes J, Shah VV, Mlacker S, et al. Vascular features of nail psoriasis using dynamic optical coherence tomography. Skin Appendage Disord 2017;2:102-8.

30. Aydin SZ, Ash Z, Del Galdo F, Marzo-Ortega H, Wakefield RJ, Emery P, et al. Optical coherence tomography: a new tool to assess nail disease in psoriasis? Dermatology 2011;222:311-3.

31. Dogra A, Arora AK. Nail psoriasis: the journey so far. Indian J Dermatol 2014;59:319-33.

32. Hashimoto Y, Uyama M, Takada Y, Yoshida K, Ishiko A. Dermoscopic features of nail psoriasis treated with biologics. J Dermatol 2017;44:538-41.

33. Yorulmaz A, Artuz F. A study of dermoscopic features of nail psoriasis. Postepy Dermatol Alergol 2017;34:28-35.

34. Klaassen KM, van de Kerkhof PC, Bastiaens MT, Plusjé LG, Baran RL, Pasch MC. Scoring nail psoriasis. J Am Acad Dermatol 2014;70:1061-6.

35. Foley P, Gordon K, Griffiths CEM, Wasfi Y, Randazzo B, Song $\mathrm{M}$, et al. Efficacy of guselkumab compared with adalimumab and placebo for psoriasis in specific body regions: a secondary analysis of 2 randomized clinical trials. JAMA Dermatol 2018;154:676-83.

36. Rich P, Bourcier M, Sofen H, Fakharzadeh S, Wasfi Y, Wang Y, et al. Ustekinumab improves nail disease in patients with moderate-to-severe psoriasis: results from PHOENIX 1. Br J Dermatol 2014;170:398-407.

37. Blauvelt A, Papp KA, Griffiths CE, Randazzo B, Wasfi Y, Shen YK, et al. Efficacy and safety of guselkumab, an anti-interleukin-23 
monoclonal antibody, compared with adalimumab for the continuous treatment of patients with moderate to severe psoriasis: results from the phase III, double-blinded, placebo- and active comparator-controlled VOYAGE 1 trial. J Am Acad Dermatol 2017;76:405-17.

38. Mease PJ. Measures of psoriatic arthritis: Tender and Swollen Joint Assessment, Psoriasis Area and Severity Index (PASI), Nail Psoriasis Severity Index (NAPSI), Modified Nail Psoriasis Severity Index (mNAPSI), Mander/Newcastle Enthesitis Index (MEI), Leeds Enthesitis Index (LEI), Spondyloarthritis Research Consortium of Canada (SPARCC), Maastricht Ankylosing Spondylitis Enthesis Score (MASES), Leeds Dactylitis Index (LDI), Patient Global for Psoriatic Arthritis, Dermatology Life Quality Index (DLQI), Psoriatic Arthritis Quality of Life (PsAQOL), Functional Assessment of Chronic Illness Therapy-Fatigue (FACIT-F), Psoriatic Arthritis Response Criteria (PsARC), Psoriatic Arthritis Joint Activity Index (PsAJAI), Disease Activity in Psoriatic Arthritis (DAPSA), and Composite Psoriatic Disease Activity Index (CPDAI). Arthritis Care Res 2011;63 Suppl 11:S64-85.

39. Rich P, Scher RK. Nail Psoriasis Severity Index: a useful tool for evaluation of nail psoriasis. J Am Acad Dermatol 2003;49:206-12.

40. Cassell SE, Bieber JD, Rich P, Tutuncu ZN, Lee SJ, Kalunian KC, et al. The modified Nail Psoriasis Severity Index: validation of an instrument to assess psoriatic nail involvement in patients with psoriatic arthritis. J Rheumatol 2007;34:123-9.

41. Parrish CA, Sobera JO, Elewski BE. Modification of the Nail Psoriasis Severity Index. J Am Acad Dermatol 2005;53:745-6;6-7.

42. Jones SM, Armas JB, Cohen MG, Lovell CR, Evison G, McHugh NJ. Psoriatic arthritis: outcome of disease subsets and relationship of joint disease to nail and skin disease. Br J Rheumatol 1994;33:834-9.

43. Williamson L, Dalbeth N, Dockerty JL, Gee BC, Weatherall R, Wordsworth BP. Extended report: nail disease in psoriatic arthritis - clinically important, potentially treatable and often overlooked. Rheumatology 2004;43:790-4.

44. Baran RL. A nail psoriasis severity index. Br J Dermatol 2004;150:568-9.

45. Cannavò SP, Guarneri F, Vaccaro M, Borgia F, Guarneri B. Treatment of psoriatic nails with topical cyclosporin: a prospective, randomized placebo-controlled study. Dermatology 2003;206:153-6.

46. de Jong EM, Menke HE, van Praag MC, van De Kerkhof PC. Dystrophic psoriatic fingernails treated with $1 \% 5$-fluorouracil in a nail penetration-enhancing vehicle: a double-blind study. Dermatology 1999;199:313-8.

47. Augustin M, Blome C, Costanzo A, Dauden E, Ferrandiz C, Girolomoni G, et al. Nail Assessment in Psoriasis and Psoriatic Arthritis (NAPPA): development and validation of a tool for assessment of nail psoriasis outcomes. Br J Dermatol 2014; 170:591-8.

48. Klaassen KM, van de Kerkhof PC, Pasch MC. Nail psoriasis: a questionnaire-based survey. Br J Dermatol 2013;169:314-9.

49. Ortonne JP, Baran R, Corvest M, Schmitt C, Voisard JJ, Taieb C. Development and validation of nail psoriasis quality of life scale (NPQ10). J Eur Acad Dermatol Venereol 2010;24:22-7.

50. Lubrano E, Scrivo R, Cantini F, Marchesoni A, Mathieu A, Olivieri I, et al. Is the Nail Psoriasis Severity Index reliable in the assessment of nail psoriasis by rheumatologists? Arthritis Care Res 2012;64:455-8.

51. Cauli A, Gladman DD, Mathieu A, Olivieri I, Porru G, Tak PP, et al. Patient global assessment in psoriatic arthritis: a multicenter GRAPPA and OMERACT study. J Rheumatol 2011;38:898-903.

52. Kavanaugh A, Catalan T, Cassell S. Patient assessments of skin, joint, and nail disease activity in psoriatic arthritis. J Rheumatol 2012;39:653.

53. Rouzaud M, Sevrain M, Villani AP, Barnetche T, Paul C, Richard
MA, et al. Is there a psoriasis skin phenotype associated with psoriatic arthritis? Systematic literature review. J Eur Acad Dermatol Venereol 2014;28 Suppl 5:17-26.

54. Balestri R, Rech G, Rossi E, Starace M, Malavolta N, Bardazzi F, et al. Natural history of isolated nail psoriasis and its role as a risk factor for the development of psoriatic arthritis: a single-centre cross-sectional study. Br J Dermatol 2017;176:1394-7.

55. Ogdie A, Gelfand JM. Clinical risk factors for the development of psoriatic arthritis among patients with psoriasis: a review of available evidence. Curr Rheumatol Rep 2015;17:64.

56. Ash ZR, Tinazzi I, Gallego CC, Kwok C, Wilson C, Goodfield M, et al. Psoriasis patients with nail disease have a greater magnitude of underlying systemic subclinical enthesopathy than those with normal nails. Ann Rheum Dis 2012;71:553-6.

57. Moya Alvarado P, Roé Crespo E, Muñoz-Garza FZ, López-Ferrer A, Laiz Alonso A, Vilarrassa Rull E, et al. Subclinical enthesopathy of extensor digitorum tendon is highly prevalent and associated with clinical and ultrasound alterations of the adjacent fingernails in patients with psoriatic disease. J Eur Acad Dermatol Venereol 2018;32:1728-36.

58. Castellanos-González M, Joven BE, Sánchez J, Andrés-Esteban EM, Vanaclocha-Sebastián F, Romero PO, et al. Nail involvement can predict enthesopathy in patients with psoriasis. J Dtsch Dermatol Ges 2016;14:1102-7.

59. Naredo E, Janta I, Baniandrés-Rodríguez O, Valor L, Hinojosa $\mathrm{M}$, Bello N, et al. To what extend is nail ultrasound discriminative between psoriasis, psoriatic arthritis and healthy subjects? Rheumatol Int 2019;39:697-705.

60. Idolazzi L, Zabotti A, Fassio A, Errichetti E, Benini C, Vantaggiato E, et al. The ultrasonographic study of the nail reveals differences in patients affected by inflammatory and degenerative conditions. Clin Rheumatol 2019;38:913-20.

61. Acquitter M, Misery L, Saraux A, Bressollette L, Jousse-Joulin S. Detection of subclinical ultrasound enthesopathy and nail disease in patients at risk of psoriatic arthritis. Joint Bone Spine 2017; 84:703-7.

62. Mondal S, Dutta S, Lahiri D, Sinha D, Sircar G, Mandal AK, et al. Assessment of nail unit structures by ultrasound in patients with psoriatic arthritis and their correlations with disease activity indices: a case-control study. Rheumatol Int 2018;38:2087-93.

63. Krajewska-Włodarczyk M, Owczarczyk-Saczonek A, Placek W, Wojtkiewicz M, Wojtkiewicz J. Effect of methotrexate in the treatment of distal interphalangeal joint extensor tendon enthesopathy in patients with nail psoriasis. J Clin Med 2018;7:546.

64. Armstrong AW, Tuong W, Love TJ, Carneiro S, Grynszpan R, Lee SS, et al. Treatments for nail psoriasis: a systematic review by the GRAPPA Nail Psoriasis Work Group. J Rheumatol 2014; 41:2306-14.

65. Crowley JJ, Weinberg JM, Wu JJ, Robertson AD, Van Voorhees AS; National Psoriasis Foundation. Treatment of nail psoriasis: best practice recommendations from the Medical Board of the National Psoriasis Foundation. JAMA Dermatol 2015;151:87-94.

66. Langley RG, Saurat JH, Reich K; Nail Psoriasis Delphi Expert Panel. Recommendations for the treatment of nail psoriasis in patients with moderate to severe psoriasis: a dermatology expert group consensus. J Eur Acad Dermatol Venereol 2012;26:373-81.

67. Mittal J, Mahajan BB. Intramatricial injections for nail psoriasis: an open-label comparative study of triamcinolone, methotrexate, and cyclosporine. Indian J Dermatol Venereol Leprol 2018;84:419-23.

68. van de Kerkhof P, Guenther L, Gottlieb AB, Sebastian M, Wu JJ, Foley $\mathrm{P}$, et al. Ixekizumab treatment improves fingernail psoriasis in patients with moderate-to-severe psoriasis: results from the randomized, controlled and open-label phases of UNCOVER-3. J Eur Acad Dermatol Venereol 2017;31:477-82. 
69. Dennehy EB, Zhang L, Amato D, Goldblum O, Rich P. Ixekizumab is effective in subjects with moderate to severe plaque psoriasis with significant nail involvement: results from UNCOVER-3. J Drugs Dermatol 2016;15:958-61.

70. Reich K, Gooderham M, Bewley A, Green L, Soung J, Petric R, et al. Safety and efficacy of apremilast through 104 weeks in patients with moderate to severe psoriasis who continued on apremilast or switched from etanercept treatment: findings from the LIBERATE study. J Eur Acad Dermatol Venereol 2018;32:397-402.

71. Busard CI, Nolte JYC, Pasch MC, Spuls PI. Reporting of outcomes in randomized controlled trials on nail psoriasis: a systematic review. Br J Dermatol 2018; 178:640-9.

72. Demirsoy EO, Kıran R, Salman S, Cağlayan C, Aktürk AS, Bayramgurler D, et al. Effectiveness of systemic treatment agents on psoriatic nails: a comparative study. J Drugs Dermatol 2013;12:1039-43.

73. Al-Mutairi N, Nour T, Al-Rqobah D. Onychomycosis in patients of nail psoriasis on biologic therapy: a randomized, prospective open label study comparing etanercept, infliximab and adalimumab. Expert Opin Biol Ther 2013;13:625-9.

74. Kyriakou A, Patsatsi A, Sotiriadis D. Anti-TNF agents and nail psoriasis: a single-center, retrospective, comparative study. J Dermatolog Treat 2013;24:162-8.

75. Saraceno R, Pietroleonardo L, Mazzotta A, Zangrilli A, Bianchi L, Chimenti S. TNF- $\alpha$ antagonists and nail psoriasis: an open, 24-week, prospective cohort study in adult patients with psoriasis. Expert Opin Biol Ther 2013;13:469-73.

76. Reich K, Sullivan J, Arenberger P, Mrowietz U, Jazayeri S, Augustin $\mathrm{M}$, et al. Effect of secukinumab on the clinical activity and disease burden of nail psoriasis: 32-week results from the randomized placebo-controlled TRANSFIGURE trial. Br J Dermatol 2018;181:954-66.

77. Coates LC, Kavanaugh A, Mease PJ, Soriano ER, Laura Acosta-Felquer M, Armstrong AW, et al. Group for Research and Assessment of Psoriasis and Psoriatic Arthritis 2015 treatment recommendations for psoriatic arthritis. Arthritis Rheumatol 2016;68:1060-71.

78. Menter A, Strober BE, Kaplan DH, Kivelevitch D, Prater EF, Stoff $\mathrm{B}$, et al. Joint AAD-NPF guidelines of care for the management and treatment of psoriasis with biologics. J Am Acad Dermatol 2019;80:1029-72.

79. Singh JA, Guyatt G, Ogdie A, Gladman DD, Deal C, Deodhar A, et al. Special article: 2018 American College of Rheumatology/ National Psoriasis Foundation guideline for the treatment of psoriatic arthritis. Arthritis Rheumatol 2019;71:5-32.

80. Elewski BE, Okun MM, Papp K, Baker CS, Crowley JJ, Guillet G, et al. Adalimumab for nail psoriasis: efficacy and safety from the first 26 weeks of a phase 3, randomized, placebo-controlled trial. J Am Acad Dermatol 2018;78:90-9.

81. Tosti A, Ricotti C, Romanelli P, Cameli N, Piraccini BM. Evaluation of the efficacy of acitretin therapy for nail psoriasis. Arch Dermatol 2009;145:269-71.
82. Feliciani C, Zampetti A, Forleo P, Cerritelli L, Amerio P, Proietto G, et al. Nail psoriasis: combined therapy with systemic cyclosporin and topical calcipotriol. J Cutan Med Surg 2004;8:122-5.

83. Abe M, Syuto T, Yokoyama Y, Ishikawa O. Improvement of quality of life and clinical usefulness of cyclosporin administration in patients with nail psoriasis. J Dermatol 2011;38:916-8.

84. Gümüşel M, Özdemir M, Mevlitoğlu I, Bodur S. Evaluation of the efficacy of methotrexate and cyclosporine therapies on psoriatic nails: a one-blind, randomized study. J Eur Acad Dermatol Venereol 2011;25:1080-4.

85. Saleem K, Azim W. Treatment of nail psoriasis with a modified regimen of steroid injections. J Coll Physicians Surg Pak 2008;18:78-81.

86. Nantel-Battista M, Richer V, Marcil I, Benohanian A. Treatment of nail psoriasis with intralesional triamcinolone acetonide using a needle-free jet injector: a prospective trial. J Cutan Med Surg 2014;18:38-42.

87. Boontaveeyuwat E, Silpa-Archa N, Danchaivijitr N, Wongpraparut C. A randomized comparison of efficacy and safety of intralesional triamcinolone injection and clobetasol propionate ointment for psoriatic nails. J Dermatolog Treat 2019;30:117-22.

88. Rigopoulos D, Gregoriou S, Lazaridou E, Belyayeva E, Apalla Z, Makris M, et al. Treatment of nail psoriasis with adalimumab: an open label unblinded study. J Eur Acad Dermatol Venereol 2010;24:530-4.

89. Khobzey K, Liskova I, Szegedi A, Pavlovsky L, Lunder T, Kingo $\mathrm{K}$, et al. Effectiveness of adalimumab in the treatment of scalp and nail affection in patients with moderate to severe plaque psoriasis in routine clinical practice. Acta Dermatovenerol Alp Pannonica Adriat 2017;26:11-4.

90. Ortonne JP, Paul C, Berardesca E, Marino V, Gallo G, Brault Y, et al. A 24-week randomized clinical trial investigating the efficacy and safety of two doses of etanercept in nail psoriasis. B J Dermatol 2013;168:1080-7.

91. Bianchi L, Bergamin A, de Felice C, Capriotti E, Chimenti S. Remission and time of resolution of nail psoriasis during infliximab therapy. J Am Acad Dermatol 2005;52:736-7.

92. Rigopoulos D, Gregoriou S, Stratigos A, Larios G, Korfitis C, Papaioannou D, et al. Evaluation of the efficacy and safety of infliximab on psoriatic nails: an unblinded, nonrandomized, open-label study. Br J Dermatol 2008;159:453-6.

93. Patsatsi A, Kyriakou A, Sotiriadis D. Ustekinumab in nail psoriasis: an open-label, uncontrolled, nonrandomized study. J Dermatolog Treat 2013;24:96-100.

94. Rigopoulos D, Gregoriou S, Makris M, Ioannides D. Efficacy of ustekinumab in nail psoriasis and improvement in nail-associated quality of life in a population treated with ustekinumab for cutaneous psoriasis: an open prospective unblinded study. Dermatology 2011;223:325-9. 